Chronic Obstructive Pulmonary Diseases:

Journal of the COPD Foundation

COPD

FOUNDATION

\author{
Clinical Review
}

\title{
Revealing Methodological Challenges in Chronic Obstructive Pulmonary Disease Studies Assessing Comorbidities: A Narrative Review
}

Sarah Houben-Wilke, $\mathrm{PhD}^{1}$ Filip J. J. Triest, $\mathrm{MD}^{1,2}$ Frits M.E. Franssen, MD, $\mathrm{PhD}^{1,2}$

Daisy J.A. Janssen, MD, $\mathrm{PhD}^{1,3}$ Emiel F.M. Wouters, MD, $\mathrm{PhD}^{1,2}$ Lowie E.G.W. Vanfleteren, MD, $\mathrm{PhD}^{1,4}$

\begin{abstract}
Beyond respiratory impairment, patients with chronic obstructive pulmonary disease (COPD) often suffer from comorbidities which are associated with worse health status, higher health care costs and worse prognosis. Reported prevalences of comorbidities largely differ between studies which might be explained by different assessment methods (objective assessment, self-reported assessment, or assessment by medical records), heterogeneous study populations, inappropriate control groups, incomparable methodologies, etc. This narrative review demonstrates and further evaluates the variability in prevalence of several comorbidities in patients with COPD and control individuals and discusses several shortcomings and pitfalls which need to be considered when interpreting comorbidity data. Like in other chronic organ diseases, the accurate diagnosis and integrated management of comorbidities is a key for outcome in COPD. This review highlights that there is a need to move from the starting point of an established index disease towards the concept of the development of multimorbidity in the elderly including COPD as an important and highly prevalent pulmonary component.
\end{abstract}

\begin{abstract}
Abbreviations: chronic obstructive pulmonary disease, COPD; Global initiative for chronic Obstructive Lung Disease, GOLD; atrial fibrillation, AF; electrocardiography, ECG; Hospital Anxiety and Depression Scale, HADS; cardiovascular disease, CVD

Funding Support: None.

Date of Acceptance: September 18, 2018

Citation: Houben-Wilke S, Triest FJJ, Franssen FME, Janssen DJA, Wouters EFM, Vanfleteren LEGW. Revealing methodological challenges in chronic obstructive pulmonary disease studies assessing comorbidities: a narrative review. Chronic Obstr Pulm Dis. 2019;6(2):166-177. doi: https://doi.org/10.15326/jcopdf.6.2.2018.0145
\end{abstract}

1 CIRO, Center of Expertise for Chronic Organ Failure, Horn, The Netherlands

2 Department of Respiratory Medicine, Maastricht University Medical Center, Maastricht, The Netherlands

3 Centre of Expertise for Palliative Care, Maastricht University Medical Center, Maastricht, The Netherlands

4 COPD Center, Sahlgrenska University Hospital and Institute of Medicine, Gothenburg University, Gothenburg, Sweden

\section{Address correspondence to:}

Dr. Sarah Houben-Wilke

Hornerheide 1

6085 NM Horn

The Netherlands

Email: sarahwilke@ciro-horn.nl

Phone: +31 (0)475 587602

\section{Keywords:}

chronic obstructive pulmonary disease; COPD; comorbidity; multimorbidity, methodology; bias; control group

\section{Introduction}

Multimorbidity is a major challenge for health care systems in the next decades. ${ }^{1}$ Beyond respiratory impairment, patients with chronic obstructive pulmonary disease (COPD) often suffer from comorbidities which are associated with worse health status, ${ }^{2}$ higher health care costs ${ }^{3}$ and worse prognosis. 4

The Global initiative for chronic Obstructive Lung 
Disease (GOLD) Global Strategy for the Diagnosis, Management, and Prevention of Obstructive Lung Disease 2017 report suggests that disease management in COPD must include identification and treatment of comorbidities. ${ }^{5}$ According to GOLD, most common comorbidities are cardiovascular disease (heart failure, ischemic heart disease, arrhythmias), peripheral vascular disease, hypertension, osteoporosis, anxiety and depression, lung cancer, metabolic syndrome and diabetes, gastroesophageal reflux, bronchiectasis and obstructive sleep apnea ${ }^{5}$ which might further be extended with skeletal muscle dysfunction and loss of muscle mass, cognitive impairment, anemia, renal insufficiency and infections. ${ }^{6}$

During the last 2 decades, publications regarding COPD and its associated comorbidities exponentially increased supporting the concept of COPD as "COmorbidity with Pulmonary Disease."7 But does this explosion of epidemiological studies and clinical trials help us to understand the association between COPD and comorbidities or does it rather cause confusion?

Reported prevalences of comorbidities largely differ between studies. For instance, the prevalence of cardiovascular diseases in patients with COPD ranges from $13 \%$ to $68 \%$ and the prevalence of mental disorders ranges from $8 \%$ to $45 \%{ }^{8}$ These discrepancies might be explained by heterogeneous study populations, incomparable methodologies, different assessment methods and diverse definitions of the respective comorbidity. Besides an appropriate study design, an adequate control group is necessary to understand and correctly interpret the prevalence at hand. Confounding variables, such as the definition of the study population, are a major potential cause of bias. ${ }^{9}$ To demonstrate and further evaluate the variability in prevalences of several comorbidities in patients with COPD and control individuals, we conducted a broad literature search (using search terms 'COPD' and 'comorbidities' in PubMed and consulting relevant references) to narratively review existing findings.

We aim to discuss several shortcomings and pitfalls which need to be considered when interpreting these data and possibly explaining part of the variance in prevalences found. Furthermore, we aim to open a discussion on future research directions related to comorbidity in COPD and on the concept of multimorbidity in the elderly with COPD as a pulmonary component.

\section{Methodologies Used to Assess Comorbidity}

Figure 1 demonstrates differences in prevalences of selected comorbidities within as well as between 3 different assessment methods: objective assessment, self-reported assessment, or assessment by medical records. Table 1 as well as e-Figures 1-3 in the online data supplement demonstrate prevalences of all comorbidities found.

\section{Figure 1. Prevalences of Cardiovascular Disease, Diabetes, Renal Impairment and Depression Stratified by Assessment Method}

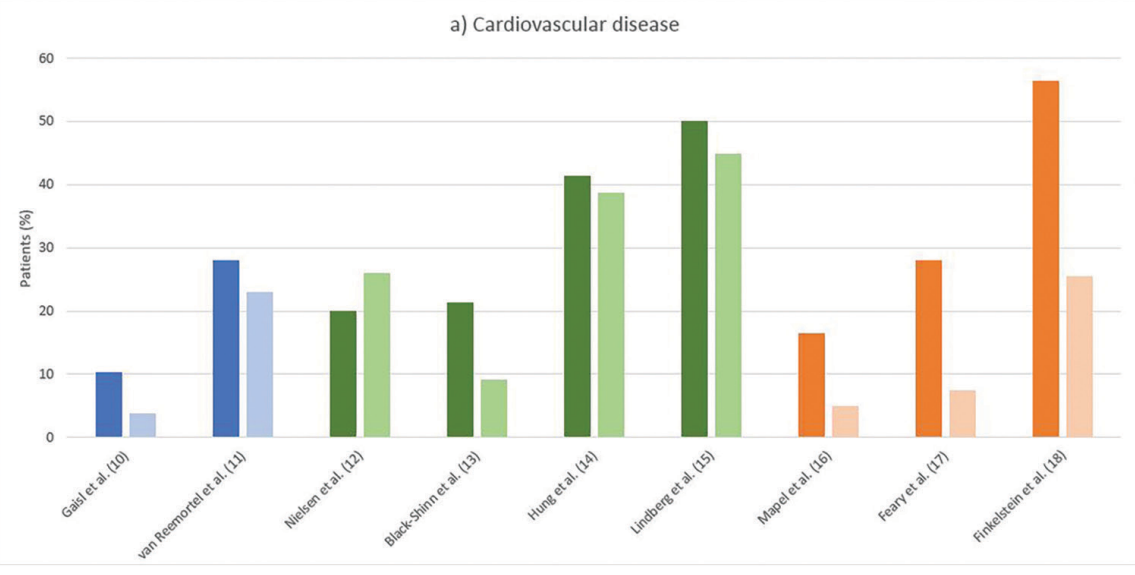




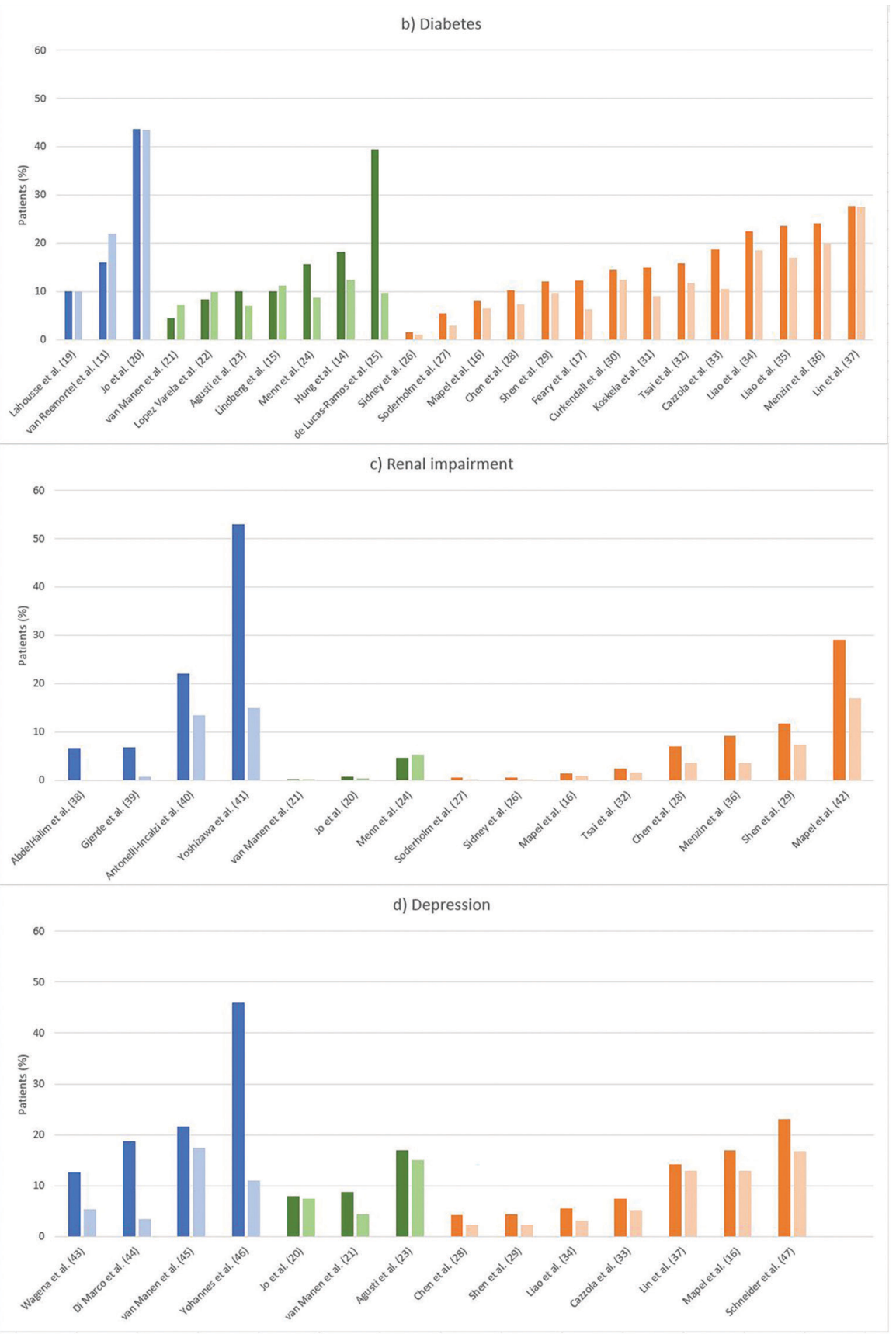

blue: objectively assessed; green: self-reported; orange: assessed by medical records; light-colored bars represent prevalences of control individuals

\section{Objective Assessment}

Objective assessment is considered an independent assessment by validated measures (without the interpretation of the individual studied). Although the objective assessment of comorbidities is generally reported as strength of a study, there are also some concerns which need to be taken into account when comparing and interpreting study findings.

First, studies might use the same assessment measure but apply a different study protocol. For instance, Konecny and colleagues and Lahousse and colleagues detected a prevalence of atrial fibrillation (AF) of $23.3 \%$ and $11 \%$, respectively, using electrocardiography (ECG) ${ }^{19,48}$; however, Konecny used a 24-hour monitoring ${ }^{48}$ probably increasing the chance of detecting an AF event while a single resting ECG had been performed in the Rotterdam study. ${ }^{49}$

Second, studies objectively assessing certain 


\section{Table 1. Prevalences Expressed as Median and Interquartile Range (If Applicable) for Each Comorbidity Stratified by Assessment Group}

\begin{tabular}{|c|c|c|c|c|c|c|}
\hline & \multicolumn{2}{|c|}{ Objectively Assessed } & \multicolumn{2}{|c|}{ Self-reported } & \multicolumn{2}{|c|}{ Medical Records } \\
\hline & COPD & Control & COPD & Control & COPD & Control \\
\hline CVD & $10^{\mathrm{a}}$ & $4^{\mathrm{a}}$ & $31(20-48)$ & $32(13-43)$ & $28(-)^{\mathrm{b}}$ & $7(-)^{\mathrm{b}}$ \\
\hline Heart disease & - & - & $16(13-24)$ & $12(11-15)$ & - & - \\
\hline HF & $3^{a}$ & $2^{\mathrm{a}}$ & $16(-)^{\mathrm{b}}$ & $1(-)^{b}$ & $11(7-17)$ & $3(2-6)$ \\
\hline MI & - & - & $9^{\mathrm{a}}$ & $3^{\mathrm{a}}$ & $7(2-13)$ & $3(1-4)$ \\
\hline IHD & $14(-)^{\mathrm{b}}$ & $13(-)^{\mathrm{b}}$ & $13(-)^{b}$ & $4(-)^{b}$ & $22(16-31)$ & $15(8-17)$ \\
\hline AF/ arrythmias & $14(-)^{\mathrm{b}}$ & $8(-)^{b}$ & $14(-)^{b}$ & $5(-)^{b}$ & $9(4-17)$ & $5(1-10)$ \\
\hline PAD & $9^{a}$ & $2^{\mathrm{a}}$ & $12(-)^{\mathrm{b}}$ & $4(-)^{b}$ & $5(2-8)$ & $2(1-4)$ \\
\hline Hypertension & $56(-)^{\mathrm{b}}$ & $48(-)^{\mathrm{b}}$ & $40(30-56)$ & $36(28-39)$ & $45(32-58)$ & $37(22-46)$ \\
\hline Anemia & $5^{a}$ & $3^{\mathrm{a}}$ & $14^{a}$ & $1^{\mathrm{a}}$ & $9^{a}$ & $6^{a}$ \\
\hline Diabetes & $16(-)^{\mathrm{b}}$ & $22(-)^{\mathrm{b}}$ & $10(8-18)$ & $10(7-11)$ & $15(10-23)$ & $10(6-17)$ \\
\hline Hypercholesterolemia/ Dyslipidemia & $76^{\mathrm{a}}$ & $79^{\mathrm{a}}$ & $32(-)^{\mathrm{b}}$ & $23(-)^{b}$ & $14(9-25)$ & $12(10-18)$ \\
\hline Metabolic Syndrome & $23(-)^{\mathrm{b}}$ & $21(-)^{\mathrm{b}}$ & - & - & $1^{\mathrm{a}}$ & $0^{\mathrm{a}}$ \\
\hline Obesity & $31^{\mathrm{a}}$ & $42^{\mathrm{a}}$ & $35^{\mathrm{a}}$ & $34^{\mathrm{a}}$ & $5(-)^{b}$ & $2(-)^{\mathrm{b}}$ \\
\hline Osteoporosis & $24(-)^{\mathrm{b}}$ & $10(-)^{\mathrm{b}}$ & $15(-)^{\mathrm{b}}$ & $4(-)^{b}$ & $15^{\mathrm{a}}$ & $11^{\mathrm{a}}$ \\
\hline Insomnia / Sleeping Problems & $41(-)^{\mathrm{b}}$ & $20(-)^{\mathrm{b}}$ & $17^{\mathrm{a}}$ & $11^{\mathrm{a}}$ & - & - \\
\hline GERD & $37(-)^{\mathrm{b}}$ & $18(-)^{\mathrm{b}}$ & $22(-)^{b}$ & $21(-)^{\mathrm{b}}$ & - & - \\
\hline Renal Impairment & $15(7-45)$ & $7(0-15)$ & $1(-)^{\mathrm{b}}$ & $0(-)^{\mathrm{b}}$ & $5(1-11)$ & $3(0-6)$ \\
\hline Brain Pathology/ Cognitive Impairment & $36(-)^{b}$ & $13(-)^{\mathrm{b}}$ & - & - & - & - \\
\hline Depression & $20(14-40)$ & $8(4-16)$ & $9(-)^{b}$ & $7(-)^{\mathrm{b}}$ & $7(4-17)$ & $5(2-13)$ \\
\hline Anxiety & $23(-)^{\mathrm{b}}$ & $6(-)^{\mathrm{b}}$ & - & - & $6^{\mathrm{a}}$ & $3^{\mathrm{a}}$ \\
\hline Psychatric/ Mental Disorders & - & - & $46^{\mathrm{a}}$ & $11^{\mathrm{a}}$ & $39(-)^{\mathrm{b}}$ & $20(-)^{b}$ \\
\hline Restless Legs & $37^{\mathrm{a}}$ & $11^{\mathrm{a}}$ & - & - & $14^{\mathrm{a}}$ & $2^{\mathrm{a}}$ \\
\hline Asthma & - & - & $23^{\mathrm{a}}$ & $11^{\mathrm{a}}$ & $27(-)^{b}$ & $2(-)^{\mathrm{b}}$ \\
\hline Stroke/ Cerebrovascular Disease & - & - & $6(-)^{b}$ & $3(-)^{b}$ & $10(6-19)$ & $5(3-9)$ \\
\hline Cancer & - & - & $10(-)^{\mathrm{b}}$ & $8(-)^{b}$ & $7(4-20)$ & $7(3-11)$ \\
\hline Lung Cancer & - & - & $0(-)^{\mathrm{b}}$ & $0(-)^{b}$ & $2^{\mathrm{a}}$ & $0^{\mathrm{a}}$ \\
\hline Ulcers/ Gastritis & - & - & $11(-)^{\mathrm{b}}$ & $7(-)^{b}$ & $3(-)^{b}$ & $2(-)^{\mathrm{b}}$ \\
\hline Liver Disease & - & - & $2(-)^{\mathrm{b}}$ & $1(-)^{\mathrm{b}}$ & $3(1-21)$ & $2(1-14)$ \\
\hline Arthritis/ Rheumatologic & - & - & $13(-)^{\mathrm{b}}$ & $9(-)^{\mathrm{b}}$ & $4(3-24)$ & $4(2-18)$ \\
\hline Locomotive Disease & - & - & $36^{\mathrm{a}}$ & $29^{\mathrm{a}}$ & - & - \\
\hline Dementia & - & - & - & - & $2(-)^{b}$ & $1(-)^{\mathrm{b}}$ \\
\hline Interstinal Disease & - & - & $6(-)^{b}$ & $4(-)^{b}$ & - & - \\
\hline Skin Disease & - & - & $4(-)^{b}$ & $3(-)^{\mathrm{b}}$ & - & - \\
\hline
\end{tabular}

comorbidities often focus on a certain research question, i.e., the comorbidity of interest, potentially ignoring other relevant findings. Ideally, investigators should be blinded to specific research questions and/or medical histories. Otherwise, consulting the medical history and medication used is necessary to accurately interpret and classify findings. For instance, assessment of hypertension by a sphygmomanometer might show unremarkable results when properly treated with antihypertensive medications. The same is true for diabetes, dyslipidemia and adequately treated depressive disorder with use of maintenance medication. Thus, objective assessment might often be a (biased) snap-shot of a current situation. In this 
context, it is a matter of debate whether or not an adequately treated or "cured" comorbidity is still a comorbidity.

Third, due to limited facilities and/or personal preferences, only a limited number of comorbidities can be assessed at a time, consequently limiting results or findings for several comorbidities in the clinic as well as literature. Indeed, as demonstrated in Figure 1, the number of comorbidities as well as studies objectively assessing comorbidities are limited compared to the rest.

Fourth, we often do not detect or assess a comorbidity at hand but we often consider several risk factors or biomarkers leading to a disease; for instance, a low bone mineral density (defined as a low t-score) is associated with a higher risk of fractures but not a disease per se. This also applies to conditions like dyslipidemia, obesity and metabolic syndrome.

Fifth, validated questionnaires might be used as objective measures although outcomes are patientreported. Furthermore, the cut-point used can differ between studies explaining part of the variance in prevalences. ${ }^{50,51}$

Sixth, for assessing psychological comorbidities, such as depression or anxiety, the generic Hospital Anxiety and Depression Scale (HADS) ${ }^{52}$ might be used. The HADS is often used as a screening instrument indicating symptoms of depression or anxiety rather than diagnosing a psychiatric disorder. Furthermore, somatic items can overlap with symptoms of COPD and side effects of medications underlining the need for a disease-specific instrument to screen and measure anxiety in patients with COPD. ${ }^{53}$

\section{Self-reported Assessment}

Compared to objective measures, subjective measures and patient recall have been demonstrated to be more variable. ${ }^{54}$ Indeed, there are several limitations which are summarized below.

First, recall periods might not be specified, specifically mentioned or properly recorded by the researcher and/or health care professional which is important, however, to understand variation which may affect the results. ${ }^{55}$ Additionally, patients might incorrectly recall or remember several events, dates and/or certain comorbidities: repeatability of selfreported clinical features, e.g., exacerbation history or childhood diagnosis of asthma, has been shown to be weak to moderate. ${ }^{54}$ Additionally, previous studies demonstrated significant knowledge gaps of patients regarding COPD and general health ${ }^{56}$ as well as prevalent cognitive impairment ${ }^{57}$ and poor health literacy ${ }^{58,59}$ possibly partly explaining the variability in patient recall.

Second, there are several relevant response bias which need to be considered. Patients might tend to give socially desirable answers or have a tendency to agree with the questions asked. In addition, ordering of questions can further influence the results or the interviewer can be biased by a specific research question, have prejudices or ask leading questions. Finally, the situation itself (e.g., being in a health care setting) might further impact the patient's response.

Third, patients might report less often diseases they do not know or understand. For instance, diabetes might be more common or understood than, for instance, renal impairment (especially in patients with impaired cognitive impairment or poor health literacy, as mentioned earlier). Patients may also recall more comorbidities which are or were meaningful for them, their autonomy and/or social environment and might less often recall comorbidities they are embarrassed about (e.g., depression) or which are not disabling.

Fourth, "self-reported" can mean as assessed by a questionnaire or by a (semi)structured interview while questionnaires are often regarded as cheap instruments with a low response rate but large sample size compared to interviews which are generally more expensive, have a high response rate, but a smaller sample size. ${ }^{9}$ Thus, to reveal further differences, the way of self-reporting can influence the results.

\section{Assessment by Medical Records}

Another possibility of studying the prevalence of comorbidities is the assessment by medical records or medical history. Using medical records can prevent or overcome recall bias by "using data recorded, for other purposes, before the outcome had occurred and therefore before the study had started. The success of this strategy is limited by the availability and reliability

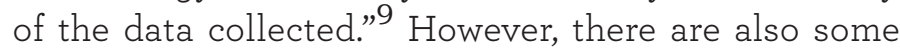
concerns which need to be taken into account.

First, although it might overcome recall bias, the question arises when the individual "medical history" starts; what is the definition (starting from birth or adulthood or date of COPD diagnosis)? This is of relevance for understanding possible causal relationships. Also, patients might be treated in 
different hospitals for different conditions and medical history may be stored in different forms (electronic/ paper), contributing to inconsistency in information.

Second, Figure 1 demonstrates that the widest range of comorbidities was recognized in comorbidities as assessed by medical records. The medical history records all relevant conditions that have ever been diagnosed in an individual. While this gives a holistic view of the patient, the number of comorbidities can be over- or underestimated as conditions may have been temporary or clinically unrecognized.

Third, an enormous range of prevalences within medical records can be observed. It is not clear (1) if the respective comorbidities are currently treated or might even be cured in the meantime and (2) which assessment has been used. Specified comorbidities in administrative data can be both, objectively assessed or self-reported, or by considering medication lists for instance. Most studies reviewed national health databases without any further specification.

Fourth, studies assessing comorbidities using medical history are often characterized by an exceptionally large population size ( $>20,000$ patients and controls ${ }^{29,34}$ ) potentially leading to significant results for all comparisons which needs to be taken into account when interpreting the results.

Fifth, there are also differences within the assessment of medical records. A recent study determined the accuracy of comorbidity information derived from electronic health records by comparing electronic health records' problem list-based comorbidity assessment with a manual review of electronic health records free-text notes in men with prostate cancer. The authors showed that problem list-based comorbidity assessment had poor sensitivity for detecting major comorbidities while free-text-based scores were predictive for mortality. ${ }^{60}$ Another study aimed to compare the number and types of comorbidities determined from medical records with 10 discharge codes obtained from the hospital administrative records and concluded that "administrative data based on hospital discharge codes consistently underestimate the presence of comorbid conditions. [...] Researchers also need to be aware when using administrative data based on hospital discharge codes to assess [patient's] comorbidities that they may be widely underreported."61

Sixth, differences in prevalences can also depend on differences in the definition of the comorbidity.
For instance, 1 study defined cardiovascular disease (CVD) as having at least 1 of the following: heart failure, poor circulation in legs, stroke, coronary heart disease, angina (angina pectoris), irregular heartbeats, or heart attack (myocardial infarction) ${ }^{18}$ whereas another defined CVD as having angina, myocardial infarction, heart failure, peripheral vascular disease and aortic aneurysm, and having undergone a previous angioplasty procedure (while cardiac arrhythmias and valvular heart disease were excluded). ${ }^{17}$

\section{Samples Studied}

As demonstrated above, even with comparable or even identical assessment methods, prevalences of particular comorbidities can still vary. Another explanation for this variance is the population studied. For example, the Rotterdam study included a population-based cohort ${ }^{49}$ while the ECLIPSE cohort specifically studied patients with COPD included in a clinical setting. ${ }^{62}$ Patients included from in- or outpatient settings are a selected population, as these patients reach out for a health care provider because of health problems. This explains smaller prevalences in population-based cohorts. Furthermore, some comorbidities might be more prevalent in more severe disease ${ }^{13}$ and patients with exacerbations may report more comorbidities or have a higher risk of developing comorbidities. ${ }^{63}$ However, there is a relevant bias: hospitalized patients or patients with more severe disease and higher health care utilization undergo more examinations consequently leading to more findings. Moreover, this selected group of patients (i.e., patients with an exacerbation) might suffer from "temporal complications" rather than "chronic comorbidities" (e.g., symptoms of anxiety and depression, hyperglycemia related to the use of systemic glucocorticosteroids).

Moreover, elderly patients with comorbid conditions are frequently excluded from clinical trials, ${ }^{64}$ also described as "comorbidity gap" between clinical studies and the elderly patient population. This limits the generalizability and external validity of scientific results to the real-world setting. ${ }^{65}$

Finally, how COPD is defined or diagnosed is relevant for the interpretation of the results. Not all studies assessed lung function to confirm the diagnosis of COPD: the diagnosis can rely on self-report ${ }^{14,43}$ or can be defined by a series of International Classification of 
Disease codes (J40: bronchitis, not specified as acute or chronic; J41: simple and mucopurulent chronic bronchitis; J42: unspecified chronic bronchitis; J43: emphysema and J44: other chronic obstructive pulmonary disease). ${ }^{66}$ Certainly, an appropriate description of the population studied is crucial to interpret and evaluate study findings.

\section{Control Group}

A control group can be defined as "a group of people without the condition of interest, or unexposed to or not treated with the agent of interest."9 A control group (i.e., non-COPD controls) is ideally similar to the experimental group (i.e., patients with COPD) in terms of relevant characteristics (e.g., risk factors) but where the factor thought to be causing an effect (i.e., COPD) is removed. For instance, compared with control individuals, patients with COPD studied by BlackShinn and colleagues ${ }^{13}$ were older, more often former smokers and had more pack years, demonstrating some selection bias. Control groups can be selected by using 1 of the following 4 techniques: (1) convenience sample, (2) matching, (3) using 2 or more control groups or (4) population-based sample for both cases and controls. ${ }^{9}$ However, with regards to convenience sample and matching, there are also some concerns which need to be taken into account.

A convenience sample for instance can reduce the external validity, while "overmatching" (too closely matched) can underestimate the true difference. ${ }^{9}$ Exclusion criteria can be too narrowed, possibly excluding relevant individuals; for instance, comorbidities are often excluded, especially in control groups referred to as "healthy participants." Indeed, Abdelhalim and colleagues excluded patients with COPD who had "chronic comorbid disease" while the only exclusion criterion for the control group were any respiratory and nonrespiratory disease. ${ }^{38}$ Furthermore, smoking is a relevant confounder which needs attention during participant selection since it influences the prevalences studied. ${ }^{67}$ Age is a crucial determinant since comorbidities evolve with ageing. Matching for gender might be relevant since several risk factors/comorbidities are more present in males/females. Finally, control groups might be recruited or extracted from other cohorts limiting the reproducibility/comparability of the results. Other potential confounders might be physical activity and/ or nutrition which are rarely reported or considered.

\section{Lessons Learned for Future Research}

Several assessment methods, differences in study populations, (in)appropriate control groups and other sources of bias make it challenging to identify a particular pattern and/or to compare study findings. This also underlines the need to pay attention to the individual patient; one might benefit from useful case studies demonstrating the complexity of an individual and treatment possibilities. Researchers are encouraged to critically evaluate methodologies used and review study findings before drawing conclusions. They should discuss their study limitations or challenges in their reports creating a learning environment for future research and/or others. To extend the generalizability and to be able to discover new relationships, exclusion criteria should not be too strict. Researchers need to be aware of recent developments in their field of interest to evaluate and/or apply innovative knowledge to their activities. For instance, $\geq 10$ pack years is often used as inclusion criterion for COPD studies. However, recent data from the COPD Genetic Epidemiology-COPDGene ${ }^{\circledR}$-cohort demonstrated that smoking duration alone provides a stronger risk estimate of COPD than pack years ${ }^{68}$ challenging this traditional approach and encouraging researchers to critically review their methodology.

Beyond the methodological differences or shortcomings, there are other, increasingly important elements which need to be taken into account when interpreting the prevalence as well as occurrence of comorbidities: scientific studies often neglect realworld situations including environmental influences (i.e., exposures) as well as the impact of time, consequently disregarding the individual complexity.

Individuals can already be exposed to environmental risk factors in utero, during perinatal life and in early childhood as well as in adulthood. ${ }^{69}$ For instance, a recent study assessed childhood predictors of lung function trajectories and future COPD risk and showed that allergic diseases, lung infections, parental asthma, and maternal smoking in early life predicted 3 unfavorable lung function trajectories. ${ }^{70}$ An impaired lung function in early adulthood has further been shown to be associated with a higher risk for early comorbidities and premature death. ${ }^{71}$ Another study presented temporal disease progression patterns using 
15 years of registry data. The authors identified COPD as a central diagnosis and demonstrated the relevance of adding the temporal dimension to understand the development of future diseases of individual patients. ${ }^{72}$ As stated before, the authors concluded that "we need [...] to identify the interactions between, on the one hand, intrinsic biological processes that drive the many chronic diseases and disabilities for which age is by far the largest risk factor and, on the other hand, the social and lifestyle factors that influence our individual trajectories of health in old age."73 Indeed, $\mathrm{Hu}$ and colleagues depicted the development of diseases using a "multimorbidity space" where patients' disease trajectories can be described as transitions between points in this space, affected by genetic and environmental parameters. ${ }^{74}$ This underlines the importance of time, ageing and the environment in the development of diseases and underlines the need for holistic approaches considering the coexistence of morbidities. To reveal the complex concept of (the development of) comorbidities including the dynamic role of time and the environment, we need to release the idea of COPD as an index disease and move from comorbidity in COPD to multimorbidity in the ageing population.

\section{Lessons Learned for Daily Practice}

Management of patients with COPD needs a holistic approach, ${ }^{8}$ considering the coexistence of morbidities with their treatments and impact on patients. ${ }^{75}$ Unraveling the underlying relationships for each patient is the determining factor for an appropriate therapeutic approach. ${ }^{76}$

In daily practice, a combination of the above described methodologies is used. A detailed and rigorous registration of self-reported and physiciandiagnosed comorbidities and verified current pharmacological therapy is an important starting point for the further objective assessment of the most relevant comorbidities in patients with COPD. Established diagnoses need to be reviewed and reevaluated whether or not follow-up is performed or indicated. In addition, the use of different pharmacological therapies needs to be evaluated on necessity, adequate dosages, and interactions with other pharmacotherapies. ${ }^{77}$

Fabbri and colleagues ${ }^{78}$ concluded that "we need to integrate our skills and treatment options between disciplines for optimal management in order to look for the synergistic effect of our efforts in contrast with the potential harmful effect of pharmacological interactions, polypharmacy and certain diseasespecific interventions. The single disease-centered clinical guidelines do not consider the reality of care for a patient with multiple chronic conditions."

Although this manuscript highlights important limitations concerning the assessment of comorbidities in COPD, there is no doubt that COPD is associated with (an increased risk of) comorbidities. However, COPD studies reporting prevalences of comorbidities should be interpreted with caution: all that glitters is not gold.

\section{Acknowledgements}

None.

\section{Declaration of Interest}

FMEF discloses consulting and speaker fees from Novartis, GlaxoSmithKline, AstraZeneca, Chiesi, Boehringer Ingelheim and Teva. LEGW discloses speaker fees from Chiesi, Novartis, GlaxoSmithKline and AstraZeneca. EFMW discloses consulting and speaker fees from Nycomed, Boehringer Ingelheim, AstraZeneca, GlaxoSmithKline, Novartis and Chiesi. SH-W, FJJT and DJAJ have nothing to disclose. 


\section{References}

1. Faner R, Cruz T, Lopez-Giraldo A, Agusti A. Network medicine, multimorbidity and the lung in the elderly. Eur Respir J. 2014;44(3):775-788.

doi: https://doi.org/10.1183/09031936.00078714

2. Wacker ME, Jorres RA, Karch A, et al. Assessing health-related quality of life in COPD: comparing generic and disease-specific instruments with focus on comorbidities. BMC Pulm Med. 2016;16(1):70. doi: https://doi.org/10.1186/s 12890-016-0238-9

3. Wacker ME, Jorres RA, Schulz H, et al. Direct and indirect costs of COPD and its comorbidities: results from the German COSYCONET study. Respir Med. 2016;111:39-46. doi: https://doi.org/10.1016/j.rmed.2015.12.001

4. Sin DD, Anthonisen NR, Soriano JB, Agusti AG. Mortality in COPD: role of comorbidities. Eur Respir J. 2006;28(6):1245-1257. doi: https://doi.org/10.1183/09031936.00133805

5. Vogelmeier CF, Criner GJ, Martinez FJ, et al. Global strategy for the diagnosis, management, and prevention of chronic obstructive lung disease 2017 report: GOLD executive summary. Am J Respir Crit Care Med. 2017;195(5): 557-582. doi: https://doi.org/10.1164/rccm.201701-0218PP

6. Franssen FM, Rochester CL. Comorbidities in patients with COPD and pulmonary rehabilitation: do they matter? Eur Respir Rev. 2014;23(131):131-141.

doi: https://doi.org/10.1183/09059180.00007613

7. Vanfleteren LE. Does COPD stand for "COmorbidity with Pulmonary Disease”? Eur Respr J. 2015;45(1):14-17. doi: https://doi.org/10.1183/09031936.00148014

8. Hillas G, Perlikos F, Tsiligianni I, Tzanakis N. Managing comorbidities in COPD. Int J Chron Obstr Pulm Dis. 2015;10(1): 95-109. doi: https://doi.org/10.2147/COPD.S54473

9. Mann CJ. Observational research methods. Research design II: cohort, cross sectional, and case-control studies. Emerg Med J. 2003;20(1):54-60.

10. Gaisl T, Schlatzer C, Schwarz E, et al. Coronary artery calcification, epicardial fat burden, and cardiovascular events in chronic obstructive pulmonary disease. Plos One. 2015;10(5):e0126613. doi: https://10.1371/journal.pone.0126613

11. Van Remoortel H, Hornikx M, Langer D, et al. Risk factors and comorbidities in the preclinical stages of chronic obstructive pulmonary disease. Am J Respir Crit Care Med. 2014;189(1):30-38.

doi: https://doi.org/10.1164/rccm.201307-12400C

12. Nielsen HM, Rødsgaard PA, Weinreich UM. Chronic obstructive pulmonary disease as comorbidity in patients admitted to a university hospital: a cross-sectional study. Clin Respir J. 2014; 8(3):274-280. doi: https://doi.org/10.1111/crj.12050 .
13. Black-Shinn JL, Kinney GL, Wise AL, et al. Cardiovascular disease is associated with COPD severity and reduced functional status and quality of life. COPD. 2014;11(5):546-551. doi: https://doi.org/10.3109/15412555.2014.898029

14. Hung WW, Wisnivesky JP, Siu AL, Ross JS. Cognitive decline among patients with chronic obstructive pulmonary disease. Am J Respir Crit Care Med. 2009;180(2):134-137. doi: https://doi.org/10.1164/rccm.200902-0276OC

15. Lindberg A. Larsson L-G, Rönmark E, Lundbäck B. Co-morbidity in mild-to-moderate COPD comparison to normal and restrictive lung function. COPD. 2011;8(6):421-428. doi: https://doi.org/10.3109/15412555.2011.629858

16. Mapel DW, Hurley JS, Frost FJ, et al. Health care utilization in chronic obstructive pulmonary disease. A case-control study in a health maintenance organization. Arch Intern Med. 160(17):26532658. doi: https://doi.org/10.1001/archinte.160.17.2653

17. Feary JR, Rodrigues LC, Smith CJ, Hubbard RB, Gibson JE. Prevalence of major comorbidities in subjects with COPD and incidence of myocardial infarction and stroke: a comprehensive analysis using data from primary care. Thorax. 2010;65(11): 956962. doi: https://doi.org/10.1136/thx.2009.128082

18. Finkelstein J, Cha E, Scharf SM. Chronic obstructive pulmonary disease as an independent risk factor for cardiovascular morbidity. Int J Chron Obstr Pulm Dis. 2009;4:337-349.

19. Lahousse L, Niemeijer MN, van den Berg ME, et al. Chronic obstructive pulmonary disease and sudden cardiac death: the Rotterdam study. Eur Heart J. 2015;36(27):1754-1761. doi: https://doi.org/10.1093/eurheartj/ehv121

20. Jo YS, Choi SM, Lee J, et al. The relationship between chronic obstructive pulmonary disease and comorbidities: a crosssectional study using data from KHANES 2010-2012. Respir Med. 2015;109(1):96-104.

doi: https://doi.org/10.1016/j.rmed.2014.10.015

21. van Manen JG, Bindels PJ, IJzermans CJ, van der Zee JS, Botteman BJ. Prevalence of comorbidity in patients with a chronic airway obstruction and controls over the age of $40 . \mathrm{J}$ Clin Epidemiol. 2001;54(3):287-293.

22. López Varela MV, Montes de Oca M, Halbert R, et al; PLATINO team. Comorbidities and health status in individuals with and without COPD in five Latin American cities; the PLATINO study. Arch Bronconeumol. 2013 Nov;49(11):468-474. doi: https://doi.org/10.1016/j.arbres.2013.05.003 .

23. Agusti A, Calverly PM, Celli B, et al; ECLIPSE investigators. Characterisation of COPD heterogenity in the ECLIPSE cohort. Respir Res. 2010;11:122. doi: https://doi.org/10.1186/1465-9921-11-122 
24. Menn P, Heinrich J, Huber RM, et al. Direct medical costs of COPD-an excess cost approach based on two population-based studies. Respir Med. 2012;106(4):540-548. doi: https://doi.org/10.1016/j.rmed.2011.10.013

25. de Lucas-Ramos P, Izquierdo-Alonso JL, Rodriguez-Gonzalez Moro JM, Frances JF, Lozano PV, Bellón-Cano JM; CONSISTE study group. Chronic obstructive pulmonary disease as a cardiovascular risk factor. Results of a case-control study (CONSISTE study). Int J Chron Obstruct Pulmon Dis. 2012;7:679686. doi: https://doi.org/10.2147/COPD.S36222

26. Sidney S, Sorel M, Quesenberry CP Jr, DeLuise C, Lanes S, Eisner MD. COPD and incident cardiovascular disease hospitalization and mortality: Kaiser Permanente Medical Care Program. Chest. 2005; 128(4):2068-2075.

27. Söderholm M, Inghammar M, Hedblad B, Egesten A, Engström G. Incidence of stroke and stroke subtypes in chronic obstructive pulmonary disease. Eur J Epidemiol. 2016;31(2):159-168. doi: https://doi.org/10.1007/s10654-015-0113-7

28. Chen SJ, Liao WC, Huang KH, et al. Chronic obstructive pulmonary disease and allied conditions is a strong independent risk factor for osteoporosis and pathologic fractures: a population-based cohort study. QJM. 2015;108(8):633-640. doi: https://doi.org/10.1093/qjmed/hcv012

29. Shen TC, Chen WC, Lin CL, et al. The risk of erectile dysfunction in chronic obstructive pulmonary disease: a population-based cohort study in Taiwan. Medicine (Baltimore). 2015;94(14):e448. doi: https://doi.org/10.1097/MD.0000000000000448

30. Curkendall SM, DeLuise C, Jones JK, et al. Cardiovascular disease in patients with chronic obstructive pulmonary disease, Saskatchewan Canada cardiovascular disease in COPD patients. Ann Epidemiol. 2006;16(1):63-70.

31. Koskela J, Kipeläinen M, Kupiainen $\mathrm{H}$, et al. Co-morbidities are the key nominators of the health-related quality of life in mild and moderate COPD. BMC Pulm Med. 2014;14:102. doi: https://doi.org/10.1186/1471-2466-14-102

32. Tsai LT, Rantakokko M, Portegijs E, et al. Environmental mobility barriers and walking for errands among older people who live alone vs. with others. BMC Public Health. 2013;13:1054. doi: https://doi.org/10.1186/1471-2458-13-1054 .

33. Cazzola M, Bettoncelli G, Sessa E, Cricelli C, Biscione G. Prevalence of comorbidities in patients with chronic obstructive pulmonary disease. Respiration. 2010;80(2):112-119. doi: https://doi.org/10.1159/000281880

34. Liao WC, Lin CL, Chang SN, Tu CY, Kao CH. The association between chronic obstructive pulmonary disease and dementia: a population-based retrospective cohort study. Eur J Neurol. 2015;22(2):334-340.

doi: https://doi.org/10.1111/ene.12573
35. Liao CC, Shih CC, Yeh CC, et al. Impact of diabetes on stroke risk and outcomes: two nationwide retrospective cohort studies. Medicine (Baltimore). 2015;94(52):e2282. doi: https://doi.org/10.1097/MD.0000000000002282

36. Menzin J, Boulanger L, Marton J, et al. The economic burden of chronic obstructive pulmonary disease (COPD) in a U.S. Medicare population. Respir Med. 2008;102(9):1248-1256. doi: https://doi.org/10.1016/j.rmed.2008.04.009

37. Lin PJ, Shaya FT, Scharf SM. Economic implications of comorbid conditions among Medicaid beneficiaries with COPD. Respir Med. 2010; 104(5):697-704.

doi: https://doi.org/10.1016/j.rmed.2009.11.009

38. AbdelHalim HA, AboElNaga HH. Is renal impairment an anticipated COPD comorbidity? Respir Care. 2016;61(9):12011206. doi: https://doi.org/10.4187/respcare.04516

39. Gjerde B, Bakke PS, Ueland T, Hardie JA, Eagan TML. The prevalence of undiagnosed renal failure in a cohort of COPD patients in western Norway. Respir Med. 2012;106(3):361-366. doi: https://doi.org/10.1016/j.rmed.2011.10.004

40. Antonelli-Incalzi R, Cosonello A, Pedone C, Battaglia S, Paglino G, Bellia V. Chronic renal failure: a neglected comobidity of COPD. Chest. 2010;137(4):831-837. doi: https://doi.org/10.1378/chest.09-1710

41. Yoshizawa T, Okada K, Furuichi S, et al. Prevalence of chronic kidney diseases in patients with chronic obstructive pulmonary disease: assessment based on glomerular filtration rate estimated from creatinine and cystatin C levels. Int J COPD. 2015;10:1283-1289. doi: https://doi.org/10.2147/COPD.S80673

42. Mapel DW, Marton JP. Prevalence of renal and hepatobiliary disease, laboratory abnormalities, and potentially toxic medication exposures among persons with COPD. Int J COPD. 2013;8:127-134. doi: https://doi.org/10.2147/COPD.S40123

43. Wagena EJ, Kant I, van Amelsvoort L, Wouters E, van Schayck C, Swaen G. Risk of depression and anxiety in employees with chronic bronchitis: the modifying effect of cigarette smoking. Psychosom Med. 2004;66(5):729-734.

doi: https://doi.org/10.1097/01.psy.0000138127.00991.cf

44. Di Marco F, Verga M, Reggente M, et al. Anxiety and depression in COPD patients: the roles of gender and disease severity. Respir Med. 2006;100(10):1767-1774.

45. van Manen JG, Bindels PJ, Dekker FW, IJzermans CJ, van der Zee JS, Schadé E. Risk of depression in patients with chronic obstructive pulmonary disease and its determinants. Thorax. 2002;57(5):412-416.

46. Yohannes AM, Roomi J, Baldwin RC, Connolly MJ. Depression in elderly outpatients with disabling chronic obstructive pulmonary disease. Age Ageing.1998;27(2):155-160. 
47. Schneider C, Jick SS, Bothner U, Meier CR. COPD and the risk of depression. Chest. 2010;137(2):341-347.

doi: https://doi.org/10.1378/chest.09-0614

48. Konecny T, Park JY, Somers KR, et al. Relation of chronic obstructive pulmonary disease to atrial and ventricular arrhythmias. Am J Cardiol. 2014;114(2):272-277.

doi: https://doi.org/10.1016/j.amjcard.2014.04.030

49. Hofman A, Darwish Murad S, van Duijn CM, et al. The Rotterdam study: 2014 objectives and design update. Eur J Epidemiol. 2013;28(11):889-926.

doi: https://doi.org/10.1007/s10654-013-9866-z

50. Slok AH, Bemelmans TC, Kotz D, et al. The Assessment of Burden of COPD (ABC) scale: a reliable and valid questionnaire. COPD. 2016;13(4):431-438.

doi: https://doi.org/10.3109/15412555.2015.1118025

51. Smid DE, Spruit MA, Houben-Wilke S, et al. Burden of COPD in patients treated in different care settings in the Netherlands. Respir Med. 2016;118:76-83.

doi: https://doi.org/10.1016/j.rmed.2016.07.015

52. Zigmond AS, Snaith RP. The hospital anxiety and depression scale. Acta Psychiatr Scand. 1983;67(6):361-370.

doi: https://doi.org/10.1111/j.1600-0447.1983.tb09716.x

53. Willgoss TG, Goldbart J, Fatoye F, Yohannes AM. The development and validation of the anxiety inventory for respiratory disease. Chest. 2013;144(5):1587-1596. doi: https://doi.org/10.1378/chest.13-0168

54. Anderson WH, Ha JW, Couper DJ, et al. Variability in objective and subjective measures affects baseline values in studies of patients with COPD. PloS One. 2017;12(9):e0184606. doi: https://doi.org/10.1371/journal.pone.0184606

55. Kjellsson G, Clarke P, Gerdtham UG. Forgetting to remember or remembering to forget: a study of the recall period length in health care survey questions. J Health Econ. 2014;35:34-46. doi: https://doi.org/10.1016/j.jhealeco.2014.01.007

56. Nakken N, Janssen DJA, van den Bogaart EHA, et al. Knowledge gaps in patients with COPD and their proxies. BMC Pulm Med. 2017;17(1):136. doi: https://doi.org/10.1186/s 12890-017-0481-8

57. Cleutjens FA, Franssen FM, Spruit MA, et al. Domain-specific cognitive impairment in patients with COPD and control subjects. Int J Chronic Obstr Pulm Dis. 2017;12:1-11. doi: https://doi.org/10.2147/COPD.S119633

58. Kale MS, Federman AD, Krauskopf $\mathrm{K}$, et al. The association of health literacy with illness and medication beliefs among patients with chronic obstructive pulmonary disease. PloS One. 2015;10(4):e0123937.

doi: https://doi.org/10.1371/journal.pone.0123937
59. Puente-Maestu L, Calle M, Rodriguez-Hermosa JL, et al. Health literacy and health outcomes in chronic obstructive pulmonary disease. Respir Med. 2016;115:78-82.

doi: https://doi.org/10.1016/j.rmed.2016.04.016

60. Daskivich TJ, Abedi G, Kaplan SH, et al. Electronic health record problem lists: accurate enough for risk adjustment? Am J Manag Care. 2018;24(1):e24-e9.

61. Powell H, Lim LL, Heller RF. Accuracy of administrative data to assess comorbidity in patients with heart disease. an Australian perspective. J Clin Epidemiol. 2001;54(7):687-693. doi: https://doi.org/10.1016/S0895-4356(00)00364-4

62. Vestbo J, Anderson W, Coxson HO, et al. Evaluation of COPD longitudinally to identify predictive surrogate end-points (ECLIPSE). Eur Respir J. 2008;31(4):869-873. doi: https://doi.org/10.1183/09031936.00111707

63. Qureshi H, Sharafkhaneh A, Hanania NA. Chronic obstructive pulmonary disease exacerbations: latest evidence and clinical implications. Ther Adv Chronic Dis. 2014;5(5):212-27. doi: https://doi.org/10.1177/2040622314532862

64. Corsonello A, Antonelli Incalzi R, Pistelli R, et al. Comorbidities of chronic obstructive pulmonary disease. Curr Opin Pulm Med. 2011;17(Suppl 1):S21-28.

doi: https://doi.org/10.1097/01.mcp.0000410744.75216.do

65. He Z, Charness N, Bian J, Hogan WR. Assessing the comorbidity gap between clinical studies and prevalence in elderly patient populations. IEEE EMBS Int Conf Biomed Health Inform. 2016;2016:136-139.

doi: https://doi.org/10.1109/BHI.2016.7455853

66. Baty F, Putora PM, Isenring B, Blum T, Brutsche M. Comorbidities and burden of COPD: a population-based case-control study. PLoS One. 2013;8(5):e63285.

doi: https://doi.org/10.1371/journal.pone.0063285

67. Houben-Wilke S, Jorres RA, Bals R, et al. Peripheral artery disease and its clinical relevance in patients with chronic obstructive pulmonary disease in the COPD and systemic consequences-comorbidities network study. Am J Respir Crit Care Med. 2017;195(2):189-197.

doi: https://doi.org/10.1164/rccm.201602-0354OC

68. Bhatt SP, Kim YI, Harrington KF, et al. Smoking duration alone provides stronger risk estimates of chronic obstructive pulmonary disease than pack-years. Thorax. 2018;73(5):414-421. doi: https://doi.org/10.1136/thoraxjnl-2017-210722

69. Postma DS, Bush A, van den Berge M. Risk factors and early origins of chronic obstructive pulmonary disease. Lancet. 2015;385(9971):899-909.

doi: https://doi.org/10.1016/S0140-6736(14)60446-3 
70. Bui DS, Lodge CJ, Burgess JA, et al. Childhood predictors of lung function trajectories and future COPD risk: a prospective cohort study from the first to the sixth decade of life. Lancet Respir Med. 2018;8(7):535-544.

doi: https://doi.org/10.1016/S2213-2600(18)30100-0

71. Agusti A, Noell G, Brugada J, Faner R. Lung function in early adulthood and health in later life: a transgenerational cohort analysis. Lancet Respir Med. 2017;5(12):935-945.

doi: https://doi.org/10.1016/S2213-2600(17)30434-4

72. Jensen AB, Moseley PL, Oprea TI, et al. Temporal disease trajectories condensed from population-wide registry data covering 6.2 million patients. Nat Commun. 2014;5:4022. doi: https://doi.org/10.1038/ncomms5022

73. Kirkwood TBL. Why and how are we living longer? Exp Physiol. 2017;102(9):1067-1074. doi: https://doi.org/10.1113/EP086205

74. Hu JX, Thomas CE, Brunak S. Network biology concepts in complex disease comorbidities. Nat Rev Genet. 2016;17(10):615629. doi: https://doi.org/10.1038/nrg.2016.87

75. Vanfleteren L, Spruit MA, Wouters EFM, Franssen FME. Management of chronic obstructive pulmonary disease beyond the lungs. Lancet Respir Med. 2016;4(11):911-924.

doi: https://doi.org/10.1016/S2213-2600(16)00097-7

76. Rogliani P, Brusasco V, Fabbri L, et al. Multidimensional approach for the proper management of a complex chronic patient with chronic obstructive pulmonary disease. Expert Rev Respir Med. 2017;12(2):1-10. doi: https://doi.org/10.1080/17476348.2018.1417041

77. Vanfleteren LE, Spruit MA, Franssen FM. Tailoring the approach to multimorbidity in adults with respiratory disease: the NICE guideline. Eur Respir J. 2017;49(2):1601696. doi: https://doi.org/10.1183/13993003.01696-2016

78. Fabbri LM, Boyd C, Boschetto P, et al. How to integrate multiple comorbidities in guideline development: article 10 in Integrating and coordinating efforts in COPD guideline development. An official ATS/ERS workshop report. Proc Am Thorac Soc. 2012;9(5):274-281.

doi: https://doi.org/10.1513/pats.201208-063ST 